\title{
Effect of adding turmeric powder to local buck rabbit's rations on some production and blood traits
}

\author{
Elham. A. El-Rawi ${ }^{1}$, Afrah.Y. Jasim ${ }^{1}$, Eman B. Ibrahim ${ }^{2}$, Fawwaz F. Ali ${ }^{1}$, Abidalbar A. Alfarha ${ }^{3}$, \\ Donea A. Abdullah. ${ }^{1}$ \\ \{elhamrawee@gmail.com, afrah_younis@ntu.edu.iq,iman.bonyan@gmail.com\}
}

\begin{abstract}
Institute of Mosul, Northern Technical University, Mosul, Iraq ${ }^{1}$, University of Dohok, Kurdistan region, Dohok, Iraq, College of Technical Agriculture, Northern Technical University, Mosul, Iraq ${ }^{3}$.
\end{abstract}

\begin{abstract}
Male rabbits are tested when turmeric powder was added to their daily food over $4-5$ weeks. The food consists of $15.8 \%$ crude protein including $2865.5 \mathrm{Kcal} / \mathrm{Kg}$ metabolizable energy. The test was carried over three sets of 10 rabbits. The turmeric was fed under a control process of 4 or $8 \mathrm{gram} / \mathrm{kg}$. These groups are classified into T1: without adding nothing, including T2 and T3 with added turmeric with 4 and 8 gram $/ \mathrm{Kg}$ respectively. The biochemical blood parameters of slaughtered rabbits are investigated and studied. Quite good results were achieved that approve the Turmeric powder has a direct influence on the production and blood traits when T1 and T2 feed control were applied and adopted.
\end{abstract}

Keywords: Rabbits, Turmeric powder, blood attributes.

\section{Introduction}

Recent studies confirm there is a good interest in the meat quality from rabbits compared to the one produced from pigs and beef [1]. It is shown that the rabbits convert $20 \%$ of protein into meat and this higher than the percentage to $16-18$ for pigs and 8-12 beef. Furthermore, the meat of the rabbit is considered a low fats meat because it's the low content of fat. In addition, this fat is low in cholesterol and saturated fatty acids [1]. All these meat features of rabbit's meat and dietary characteristics are increasing the values of this type of meat in the meat industry. Taking under consideration that the rabbit's meat production was reached $1,141,893$ tons in 2005 globally [2]. The evaluation of rabbit's meat performance and carcass traits are commonly the main variables used to evaluate the rabbit meat production process. In recent eras, numerous efforts have been made to develop alternatives to antibiotics in order to maintain livestock health; improve animal production, and to enhance the carcass characters [3]. Likewise, Rabbit meat also contains a higher proportion of essential, unsaturated fatty acids, including linoleic, and linolenic, these fatty acids represent a $36 \%$ of the total fatty acids in the rabbit's fat. The high demand to identify alternative natural and suitable sources of food antioxidants has increasingly arisen. So, this leads to an increase in the search for natural antioxidants, in particular from plant origin, as highly considered in recent years.

Antioxidants widely considered as food additives to protect against the oxidative degradation of foods like this turmeric [4-6]. The popular herb derived Turmeric has a strong yellow colour [7], and is produced by its polyphenol constituent, curcumin (diferuloylmethane). Curry powder is isolated from the rhizome of the plant Curcuma longa. Apart from its application as foodcoloring agent Curcumin, a hydrophobic polyphenol derived from the rhizome of the 
herb Curcuma longa has a broad spectrum of biological and pharmacological activities. It also affects to enhance the animal's growth and performance [8]. Chemically, curcumin is a bis-R,unsaturated-diketone commonly called diferuloylmethane [9]. Many studies showed that curcumin exhibits antimicrobial activity [10], anti-inflammatory antitumor and ant oxidative properties [11-13], and enhance liver enzyme [14]. Moreover, it has been indicated hypolipidemic effects of turmeric and curcumin $[15,16]$. And it has been found the effect to decrease the cholesterol level in humans [17] and in rabbits which suggested the role to manage the cardiovascular disease [12]. Furthermore, it has been indicated the beneficial role of turmeric extract in other diseases and disorders including obesity, diabetes and liver disease [18-21]; whereas to the anti-inflammatory effects the immune system [22-24]. So, this study investigates the effect of the inclusion of turmeric powder in diets on fattening rabbits and some blood biochemical traits.

\section{Materials and Methods:}

The experiment took place in the Al-Huda Al-Ahly field in the Tall-Kaif region at Nineveh province. Thirty local male rabbits, aged about (4-5 weeks) with mean weight $(534 \pm 1.5 \mathrm{~g}$ ) was used to study the effect of turmeric powder on fattening rabbits. Three treatments were randomly divided into three groups (10 rabbits/group) and five replications ( 2 rabbits in each repeater) for each group and put repeater (10 bis) in cages made of wood and wire clamp and placed in the hall. The chamber containing a vacuum pump (for the introduction of fresh air) and room light regulator supported by an electric lamp. For 16 hours a day, Ration was provided manually, daily and the time specified and fixed for all the groups with libitum water, This study used ration and one (Table 1) with the proportion of protein $(16.12 \%)$ and the amount of energy calculated in Ration is $2684 \mathrm{kcal} / \mathrm{kg}$ feed, according to [25]. and provided the same Ration to all transactions, Add turmeric powder to the second and third treatment, as follows:

- The first treatment: ration control.

- The second treatment: ration control $+4 \mathrm{~g}$ turmeric powder $/ \mathrm{kg}$ ration.

- The third treatment: ration control circuit $+8 \mathrm{~g}$ turmeric powder $/ \mathrm{kg}$ ration.

The feed conversion was determined by calculating the amount of feed that required for production and increasing the body weight (g, feed/g, gain) (Table 2) as the following equation:

\section{$F C R=$ Feed consumption / Body weight gain}

At the end of the feeding period ( 8 weeks), the final weight was determined (Table 2) as the following equation:

$$
B W I=((\text { final body weight }- \text { Initial body weight }) / \text { Initial body weight }) \times 100
$$

Then all rabbits from treatments were determined the carcass parameters according to [6]. Rabbits had fasted for 12 hours and weighted then slaughtered based on Islamic rules. Edible offal's (Giblets) that include heart, liver, kidneys, lungs, spleen, and testes were removed and individually weighed. Full and empty weights of small and large intestines were recorded, and contents of small and large intestines were calculated by differences between full/empty and small/large. The hot carcass was weighed and divided into fore, middle and hind parts. The 
blood from each rabbit was extracted and the meat considered for the study. Thirty blood samples were processed for heparinized test tubes and centrifuged at $3000 \mathrm{rpm}$ for 15 minutes. The plasma was collected and preserved in a deep freezer at $-18^{\circ} \mathrm{C}$ up to the time of analysis. The total protein in the plasma was calculated as in [26]. Plasma Glutamic Oxaloacetic Transaminase (GOT) and Glutamic Pyruvic Transaminase (GPT) activities were determined as in [27]. Triglycerides and total cholesterol using a kit factory by the company (Bio Labo Reagents, Mazy. France) was determined according to [28].

A statistical method applied to adopt the model procedure of SPSS (2000). To separate the resources of the elements, Duncan's Multiple Range Test (1955) was used for the dietary treatment effect.

\section{The following model was used:}

$Y i j=\mu+t i+e i j$

Yij= Experiment observations.

$\mu=$ the overall mean.

$\mathrm{ti}=$ The effect of dietary treatment

$\mathrm{eij}=$ The experimental error.

\section{Results and discussion:}

\subsection{The qualities of Productivity:}

The qualities Productivity: Table 2 shows Supplementation of turmeric powder were significant in the final weight, weight gain, feed intake, feed conversion ratio and relative growth ratio in T2 and T3 when compared to control, Attributed the increase in the body weight gain to the antioxidant activity of Curcuma longa [29]. The results are in concurrence with the supplementation of turmeric (Curcuma longa) increases the growth of broilers when added at the rate of $0.75 \%$ level as feed additives in broiler ration [30] or a significant increase in body weight in $\mathrm{T} 2+\mathrm{T} 3$. Turmeric powder may be due to the optimum antioxidant activity of turmeric (Curcuma longa) that can stimulate protein synthesis enzymatic system [31]. The results presented by [32] reported that the growth is enhanced by using curcuminoids and curcumin. A high potential for the use of turmeric extract that prevents pathogenic bacteria in chicken [33].

\subsection{Carcass characteristics:}

The obtained results in this study are illustrated in the table (3); there were signs in the hot carcass and dressing percentages in treatments $(\mathrm{T} 2+\mathrm{T} 3)$. This difference may be due to an increase in the weight $(0,0.05)$ of hot and cold carcasses, which is based on the addition of 8 $\mathrm{kg} / \mathrm{kg}$ of calmer powder, which is attributed to the final weight before slaughtering the rabbits fed on the mentioned breeds. This moral difference in the weight of the carcass reflects moral superiority (00.05) in the dressing percentage or enhanced the antioxidant enzyme activity [34].

\subsection{Some blood parameters:}

Some blood parameters. Table (4) indicated that (TP), ALT and AST remained unchanged significantly in all tested group rabbits. Table (4) it also indicates cholesterol and triglyceride concentration was significantly $(\mathrm{p}<0.05)$ lower at $(4 \mathrm{~g}$ and $8 \mathrm{~g}) \mathrm{TP} / \mathrm{kg}$ diet,. The decrease of total lipid and cholesterol may be due to the effect of essential oil compounds present in the turmeric 
on lipid metabolism [35], or due to curcumin, that enhances bile production and hence lipid digestion [29]. It has been showed that liver triacylglycerol and cholesterol concentrations were considerably less in rats fed curcumin than in control animals [36].

Table 1: Composition of the rabbit's diet (for $100 \mathrm{~kg}$ feed)

\begin{tabular}{cc}
\hline Foodstuff & \% \\
\hline Barley Black & 32 \\
Yellow corn & 19 \\
Wheat & 10 \\
Wheat bran & 25 \\
Soybean meal & 12 \\
Bentonite & 0,5 \\
Sodium chloride & 0,5 \\
A mixture of vitamins & 1 \\
Limestone & 0,5 \\
& \\
Chemical analysis of the diets\% & \\
Dry matter * & 91.149 \\
NFE & 60.55 \\
E.E & 2,36 \\
Fiber * & 6.909 \\
Ash $*$ & 5.53 \\
Crude protein $*$ & 15.8 \\
M.E Kcal/kg & 2865.5 \\
DE (kcal/ kg DM) & 3229.2346 \\
\hline
\end{tabular}

$\mathrm{DE}$ in $\mathrm{kcal} / \mathrm{kg} \mathrm{DM}=4253-32.6(\mathrm{CF} \%)-144.4($ total ash \%) [17].

Table 2: the effect of added Turmeric powder to diet on rabbit performance for three months.

\begin{tabular}{llll}
\hline \multicolumn{1}{c}{ Parameters } & Control & \multicolumn{1}{c}{ T2 } & \multicolumn{1}{c}{ T3 } \\
\hline The number of animals & 10 & 10 & 10 \\
Initial weight $(\mathrm{g})$ & $542.13 \pm 50$ & $537.02 \pm 55$ & $535.29 \pm 45$ \\
Final weight $(\mathrm{g})$ & $1023.221 \pm 66 \mathrm{c}$ & $1133.008 \pm 61 \mathrm{~b}$ & $1203.039 \pm 52 \mathrm{a}$ \\
weight gain $(\mathrm{g}$ & $481.091 \pm 24 \mathrm{c}$ & $595.988 \pm 35 \mathrm{~b}$ & $667.749 \pm 41 \mathrm{a}$ \\
feed intake $(\mathrm{g}) /$ & $2656.77 \pm 32$ & $2768.102 \pm 44$ & $2867.045 \pm 32$ \\
Feed conversion ratio & $5.522 \pm 24$ & $4.644 \pm 24$ & $4.293 \pm 17$ \\
Relative growth rate\% & $61.467 \pm 24$ & $71.374 \pm 24$ & $76.826 \pm 24$ \\
$\begin{array}{l}\text { Digestion coefficient of dry } \\
\text { matter }(\%)\end{array}$ & $63.688 \pm 24$ & $65.354 \pm 24$ & $67.277 \pm 24$ \\
\hline
\end{tabular}


Relative growth rate $=[(\mathrm{W} 2-\mathrm{W} 1) \times 100] /[1 / 2(\mathrm{~W} 2+\mathrm{W} 1)]$ Whereas: $\mathrm{W} 1=$ the initial weight, and $\mathrm{W} 2=$ the final body weight Performance index $=($ final live body weight $(\mathrm{kg}) /$ feed conversion ratio) $\mathrm{x} 100$ [19].

Table 3: Carcass characteristics.

\begin{tabular}{llll}
\hline \multicolumn{1}{c}{ Parameters } & \multicolumn{1}{c}{$\mathrm{T} 1$} & \multicolumn{1}{c}{$\mathrm{T}$} & \multicolumn{1}{c}{$\mathrm{T} 3$} \\
\hline Final weight $(\mathrm{g})$ & $1023.221 \pm 66 \mathrm{c}$ & $1133.008 \pm 61 \mathrm{~b}$ & $1203.039 \pm 52 \mathrm{a}$ \\
Hot Carcass & $529.752 \pm 43 \mathrm{c}$ & $679.793 \pm 52 \mathrm{~b}$ & $723.820 \pm 74 \mathrm{a}$ \\
Cold carcass & $509.748 \pm 26$ & $659.730 \pm 58$ & $703.817 \pm 48$ \\
liver & $17.383 \pm 25$ & $19.077 \pm 32$ & $18.014 \pm 43$ \\
heart & $1.661 \pm 13$ & $1.862 \pm 24$ & $2.022 \pm 17$ \\
kidneys & $4.121 \pm 0.4$ & $4.104 \pm 0.6$ & $4.202 \pm 0.3$ \\
Dressing percentage & $51.772 \pm 23 \mathrm{c}$ & $59.999 \pm 36 \mathrm{~b}$ & $60.166 \pm 15 \mathrm{a}$ \\
\hline
\end{tabular}

Table 4: Blood plasma elements of the tested samples.

\begin{tabular}{llll}
\hline Item & T1 & T2 & T3 \\
\hline Total protein $(\mathrm{g} / \mathrm{dl})$ & $5.34 \pm 0.15$ & $5.38 \pm 0.01$ & $5.35 \pm 0.13$ \\
Cholesterol $(\mathrm{mg} / 100 \mathrm{ml})$ & $140.03 \pm 0.03 \mathrm{a}$ & $120.271 \pm 0.03 \mathrm{~b}$ & $116.027 \pm 0.01 \mathrm{~b}$ \\
Triglycerides $(\mathrm{mg} / 100 \mathrm{ml})$ & $35.08 \pm .050 \mathrm{a}$ & $27.06 \pm 0.23 \mathrm{~b}$ & $25.393 \pm 0.02 \mathrm{~b}$ \\
GOT $(\mathrm{U} / \mathrm{ml})$ & $51.03 \mathrm{a} \pm 2.10$ & $48.99 \mathrm{~b} \pm 0.31$ & $50.45 \mathrm{c} \pm 0.53$ \\
GPT $(\mathrm{U} / \mathrm{ml}$ & $30.06 \pm 0.66$ & $28.73 \pm 0.05$ & $27.90 \pm 0.18$ \\
\hline
\end{tabular}

\section{Conclusions}

Based on the experimental findings, we state that turmeric could have beneficial effects on performance, digestibility, and growth promoter. And this may improve the performance and some of the rabbit's carcass traits. The results also support the significant role of turmeric in immunomodulation, also, it may have an important role as an exogenous antioxidant.

\section{Acknowledgments:}

The authors acknowledge the Al-Huda Al-Ahly field in the Tall-Kaif region at Nineveh province, and the /Institute of Mosul, Northern Technical University, Mosul, Iraq, to support the current research.

\section{References:}

[1] P. Hernandez, Enhancement of nutritional quality and safety in rabbits;, Proceedings of the 9th World Rabbit Congress, Verona, Italy, 2008, pp. 1287-1299.

[2] FAO, Food and Agriculture Organization of the United Nations,. Faostat agriculture data, 2006.

[3] A. Abdel-Wareth, S. Kehraus, F. Hippenstiel, K.H. Südekum, Effects of thyme and oregano on growth performance of broilers from 4 to 42 days of age and on microbial counts 
in crop, small intestine and caecum of 42-day-old broilers., J Anim Feed Sci Technol. 178 (2011) 198-202.

[4] S. Mancini, G. Preziuso, A. Dal Bosco, V. Roscini, Z. Szendro, F. Fratini, G. Paci, Effect of turmeric powder (Curcuma longa L.) and ascorbic acid on physical characteristics and oxidative status of fresh and stored rabbit burgers, Meat Sci 110 (2015) 93-100.

[5] B. Alharbi, L. Fadda, H.M. Ali, Evaluation of the renoprotective effect of nano turmeric against toxic dose of copper sulfate: Role of vascular cell adhesion molecule-1, kidney injury molecule-1, and signal transducer and activator of transcription 3 protein expressions, $\mathrm{J}$ Biochem Mol Toxicol 33(2) (2019) e22243.

[6] I.K. Bae, K.J. Kim, J.S. Choi, Y.I. Choi, J.H. Ha, Quality Properties and Storage Characteristics of Pyeonyuk with Different Additional Levels of Turmeric Powder, Food Sci Anim Resour 39(1) (2019) 35-44.

[7] Turmeric, LiverTox: Clinical and Research Information on Drug-Induced Liver Injury, Bethesda (MD), 2012.

[8] O.A. Oderinwale, B.O. Oluwatosin, M.O. Onagbesan, A.O. Akinsoyinu, S.D. Amosu, Performance of kids produced by three breeds of goat fed diets supplemented with graded levels of turmeric powder, Trop Anim Health Prod 52(3) (2020) 1239-1248.

[9] O.P. Sharma, Antioxidant activity of curcumin and related compounds, Biochemical pharmacology 25(15) (1976) 1811-2.

[10] H. Bangun, A. Arianto, Y.S. Bangun, M. Nainggolan, Antibacterial Activity of

Mucoadhesive Gastroretentive Drug Delivery System of Alginate Beads Containing Turmeric Extract - PVP Solid Dispersion, Open Access Maced J Med Sci 7(22) (2019) 3868-3873.

[11] T.H. Leu, M.C. Maa, The molecular mechanisms for the antitumorigenic effect of curcumin, Current medicinal chemistry. Anti-cancer agents 2(3) (2002) 357-70.

[12] M.C. Ramirez-Tortosa, M.D. Mesa, M.C. Aguilera, J.L. Quiles, L. Baro, C.L. RamirezTortosa, E. Martinez-Victoria, A. Gil, Oral administration of a turmeric extract inhibits LDL oxidation and has hypocholesterolemic effects in rabbits with experimental atherosclerosis, Atherosclerosis 147(2) (1999) 371-8.

[13] Y. Choi, I. Ban, H. Lee, M.Y. Baik, W. Kim, Puffing as a Novel Process to Enhance the Antioxidant and Anti-Inflammatory Properties of Curcuma longa L. (Turmeric), Antioxidants (Basel) 8(11) (2019).

[14] A. Blasco, J. Outhayoun, G. Masoero, Harmonization of criteria and terminology in rabbit meat research, World Rabbit Sci. 1(1) (1993) 3-10.

[15] V.P. Dixit, P. Jain, S.C.H.e.o.C.1.L.a.N. Joshi, DC in triton-induced hyperlipidaemic rats.y., Hypolipidaemic effects of Curcuma longa L. and Nardostachysjatamansi, DC in tritoninduced hyperlipidaemic rats, Indian Journal of Physiology and Pharmacolog 32 (1998) 299304.

[16] P.S. Babu, K. Srinivasan, Hypolipidemic action of curcumin, the active principle of turmeric (curcuma longa) in streptozotocin induced diabetic rats, Molecular and Cellular Biochemistry, 166 (1997) 169-175.

[17] Z. Adab, S. Eghtesadi, M.R. Vafa, I. Heydari, A. Shojaii, H. Haqqani, T. Arablou, M. Eghtesadi, Effect of turmeric on glycemic status, lipid profile, hs-CRP, and total antioxidant capacity in hyperlipidemic type 2 diabetes mellitus patients, Phytother Res 33(4) (2019) 11731181.

[18] A. Ghaffari, M. Rafraf, R. Navekar, B. Sepehri, M. Asghari-Jafarabadi, S.M. Ghavami, Turmeric and chicory seed have beneficial effects on obesity markers and lipid profile in nonalcoholic fatty liver disease (NAFLD), Int J Vitam Nutr Res 89(5-6) (2019) 293-302. 
[19] R. Essa, A.M. El Sadek, M.E. Baset, M.A. Rawash, D.G. Sami, M.T. Badawy, M.E. Mansour, H. Attia, M.K. Saadeldin, A. Abdellatif, Effects of Turmeric (Curcuma longa) Extract in streptozocin-induced diabetic model, J Food Biochem 43(9) (2019) e12988. [20] R. Goodarzi, K. Sabzian, F. Shishehbor, A. Mansoori, Does turmeric/curcumin supplementation improve serum alanine aminotransferase and aspartate aminotransferase levels in patients with nonalcoholic fatty liver disease? A systematic review and meta-analysis of randomized controlled trials, Phytother Res 33(3) (2019) 561-570.

[21] E. Hay, A. Lucariello, M. Contieri, T. Esposito, A. De Luca, G. Guerra, A. Perna, Therapeutic effects of turmeric in several diseases: An overview, Chem Biol Interact 310 (2019) 108729.

[22] E. Joe, U. J., S.P. Rao, L. R., Presence of an acidic glycoprotein in the serum of arthritic rats: modulation by capsaicin and curcumin., Molecular and Cellular Biochemistry, 169

(1997) 125-134.

[23] E.H. South, J.H. Exon, Dietary curcumin enhances antibody response in rats, Immunopharmacology and Immunotoxicology 19 (1997) 105-119.

[24] F. Ghiamati Yazdi, S. Soleimanian-Zad, E. van den Worm, G. Folkerts, Turmeric Extract: Potential Use as a Prebiotic and Anti-Inflammatory Compound?, Plant Foods Hum Nutr 74(3) (2019) 293-299.

[25] N.R.C. (NRC), Nutrient Requirement Of Rabbits National Academy Press, USA, 1977.

[26] C.A. Burits, E.R. Ashwood, A Textbook of Clinical chemistry, 3rd ed., W. B.

Saunders1999.

[27] S. Reitman, S. Frankel, A colorimetric method for the determination of serum glutamic oxalacetic and glutamic pyruvic transaminases, American journal of clinical pathology 28(1) (1957) 56-63.

[28] S.C. Co, Quantitative determination of cholesterol in high density lipoprotein (HDL) fraction of serum or plasma, Tech. bull., No. 356. St. Louis., 1990.

[29] S.I. Al-Sultan, A.A. Gameel, (2004).. Histopathological changes in the livers of broiler chicken supplemented with turmeric (Curcuma longa). Int. J. Poultry Sci 3 (2004) 333-336.

[30] A. Kafi, M.N. Uddin, M.J. Uddin, M. Khan, E. Haque, Effect of Dietary Supplementation of Turmeric (Curcuma longa), Ginger (Zingiber officinale) and their Combination as Feed Additives on Feed Intake, Growth Performance and Economics of Broiler, (2017).

[31] F.R. Durrani, M. Ismail, A. Sultan, S.M. Suhail, N. Chand, Z. Durrani, Effect of different levels of feed added turmeric (Curcuma longa) on the Performance of Broiler Chicks, Journal of Agriculture and Biological Science, 1 (2006) 9-11.

[32] S.N. Hussein, Effect of Turmeric (Curcuma longa) powder on growth performance, carcass traits, meat quality, and serum biochemical parameters in broilers, Journal of Advanced Biomedical and Pathobiology Research 3 (2012) 25-32.

[33] L. Ong-ard, K. Ngampong, K. Boonsong, Antimicrobial activity of curcuminoids from Curcuma longa L. on pathogenic bacteria of shrimp and chicken. Kasetsart, J. Nat. Sci. 44 (2010) 364- 371.

[34] J. Nm, A. Joseph, B. Maliakel, K. Im, Dietary addition of a standardized extract of turmeric (TurmaFEED(TM)) improves growth performance and carcass quality of broilers, $\mathrm{J}$ Anim Sci Technol 60 (2018) 8.

[35] N.L. Radwan, R.A. Hassan, E.M. Qota, H.M. Fayek, Effect of natural antioxidant on oxidative stability of eggs and productive and reproductive performance of laying hens, International Journal of Poultry Science, 7(2) (2008) 134-50. 
[36] A. Asai, T. Miyazawa, Dietary Curcuminoids Prevent High-Fat Diet-Induced Lipid Accumulation in Rat Liver and Epididymal Adipose Tissue, The Journal of Nutrition 131(11) (2001) 2932-2935. 